University of Nebraska - Lincoln

DigitalCommons@University of Nebraska - Lincoln

Publications, Agencies and Staff of the U.S.

Department of Commerce

U.S. Department of Commerce

2011

\title{
The evolutionary origins of Syngnathidae: pipefishes and seahorses
}

A. B. Wilson

Institute of Evolutionary Biology and Environmental Studies, tony.wilson@ieu.uzh.ch

J. W. Orr

NOAA

Follow this and additional works at: https://digitalcommons.unl.edu/usdeptcommercepub

Part of the Environmental Sciences Commons

Wilson, A. B. and Orr, J. W., "The evolutionary origins of Syngnathidae: pipefishes and seahorses" (2011). Publications, Agencies and Staff of the U.S. Department of Commerce. 331.

https://digitalcommons.unl.edu/usdeptcommercepub/331

This Article is brought to you for free and open access by the U.S. Department of Commerce at DigitalCommons@University of Nebraska - Lincoln. It has been accepted for inclusion in Publications, Agencies and Staff of the U.S. Department of Commerce by an authorized administrator of DigitalCommons@University of Nebraska - Lincoln. 


\title{
The evolutionary origins of Syngnathidae: pipefishes and seahorses
}

\author{
A. B. WILSON*† AND J. W. ORR $\ddagger$ \\ *Institute of Evolutionary Biology and Environmental Studies, Winterthurerstrasse 190, 8057 \\ Zurich, Switzerland and $\$$ Resource Assessment and Conservation Engineering Division, \\ Alaska Fisheries Science Center, National Marine Fisheries Service, NOAA, 7600 Sand Point \\ Way NE, Seattle, WA 98115, U.S.A.
}

\begin{abstract}
Despite their importance as evolutionary and ecological model systems, the phylogenetic relationships among gasterosteiforms remain poorly understood, complicating efforts to understand the evolutionary origins of the exceptional morphological and behavioural diversity of this group. The present review summarizes current knowledge on the origin and evolution of syngnathids, a gasterosteiform family with a highly developed form of male parental care, combining inferences based on morphological and molecular data with paleontological evidence documenting the evolutionary history of the group. Molecular methods have provided new tools for the study of syngnathid relationships and have played an important role in recent conservation efforts. Despite recent insights into syngnathid evolution, however, a survey of the literature reveals a strong taxonomic bias towards studies on the species-rich genera Hippocampus and Syngnathus, with a lack of data for many morphologically unique members of the family. The study of the evolutionary pressures responsible for generating the high diversity of syngnathids would benefit from a wider perspective, providing a comparative framework in which to investigate the evolution of the genetic, morphological and behavioural traits of the group as a whole.

(C) 2011 The Authors Journal of Fish Biology (c) 2011 The Fisheries Society of the British Isles
\end{abstract}

Key words: fossil evidence; Gasterosteiformes; morphology; phylogenetics; phylogeography.

\section{INTRODUCTION}

The Syngnathidae (seahorses and pipefishes) are a large family of close to 300 marine, brackish and freshwater species (Froese \& Pauly, 2010), all of which share an exceptional form of reproduction, male pregnancy (Wilson et al., 2001; Stölting \& Wilson, 2007). This key feature of the group has made them important model organisms for the study of sexual selection (Clutton-Brock \& Vincent, 1991; Kvarnemo \& Ahnesjö, 2002; Berglund \& Rosenqvist, 2003; Wilson et al., 2003; Jones et al., 2005).

In addition to their unique reproductive behaviour, syngnathids are well known for their highly specialized morphology, and the diversity of morphological forms found in this group has complicated efforts to understand their evolutionary origins and pattern of diversification. This exceptional morphological variation is reflected in the current taxonomy of the group: 14 of the 54 currently recognized syngnathid genera are monotypic (Froese \& Pauly, 2010), and the majority of genera are composed of fewer than three species.

$†$ †uthor to whom correspondence should be addressed. Tel.: +41 44635 4790; email: tony.wilson@ ieu.uzh.ch 
The family Syngnathidae has traditionally been included as a member of the order Gasterosteiformes, which includes 11 families in two suborders: the Gasterosteoidei, with the Hypoptychidae, Gasterosteidae and Aulorhynchidae; and the Syngnathoidei, with the Indostomidae, Aulostomidae, Fistulariidae, Macroramphosidae, Centriscidae, Pegasidae, Solenostomidae and Syngnathidae. The evolutionary history of the Gasterosteiformes itself has been the subject of controversy since its inception because of the derived and highly reductive morphology of its constituent families. Major monophyletic groups of families within the Gasterosteiformes have long been recognized, including Gasterosteidae and Aulorhynchidae (as superfamily Gasterosteoidea), Aulostomidae and Fistulariidae (Aulostomoidea), Centriscidae and Macroramphosidae (Centriscoidea), and Syngnathidae and Solenostomidae (Syngnathoidea) (Fig. 1; Orr, 1995). Studies using morphology have proposed monophyly of the order and suggested sister groups based on weak evidence, and while the close relationships of superfamilies is well supported (Fig. 1), the relationships among these family pairs remains unclear (Pietsch, 1978; Johnson \& Patterson, 1993; Orr, 1995; Keivany \& Nelson, 2006). In contrast, molecular evidence clearly refutes the monophyly of the Gasterosteiformes, placing gasterosteoids close to the cottoid-zoarcoid lineage (Imamura \& Yabe, 2002), excluding the Indostomidae, and placing both groups distant from syngnathoids. While the sister group of syngnathoids remains unknown and the relationships among syngnathoid lineages are poorly resolved, the family Solenostomidae (ghost pipefishes) has been faithfully recovered as the sister group of the Syngnathidae in both morphological and molecular analyses, an evolutionary relationship key to understanding the evolution of male parental care in the family Syngnathidae.

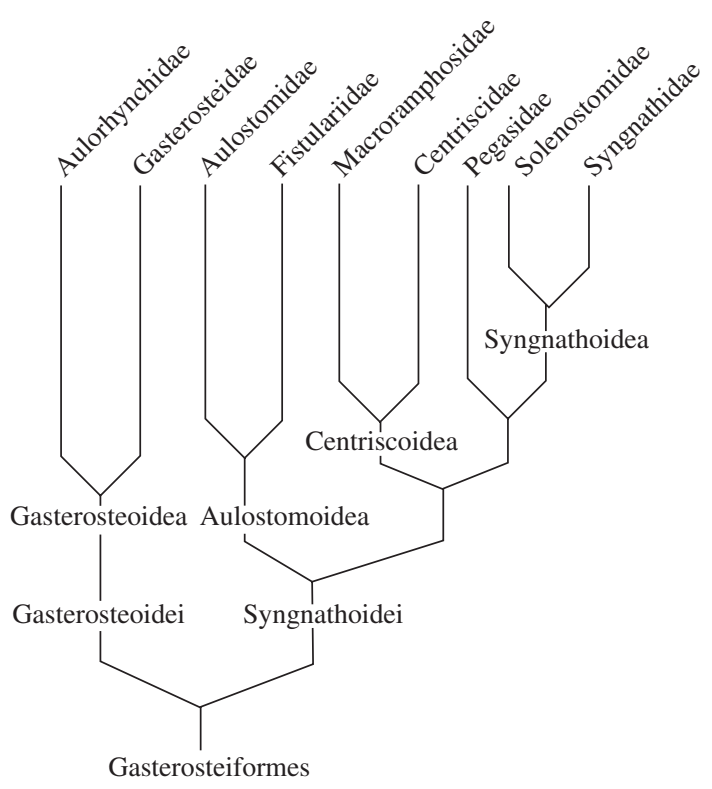

FIG. 1. Phylogenetic relationships and superfamily classification of the Gasterosteiformes based on morphological analysis (after Orr, 1995). Note: the Hypoptychidae and Indostomidae are excluded from this classification scheme (see Fig. 2 for other hypotheses on higher level relationships in this group). 


\section{HIGHER LEVEL PHYLOGENETICS: MORPHOLOGY VS. MOLECULES}

\section{MORPHOLOGICAL ANALYSES}

Linnaeus (1758) codified the prevailing concept of a wide separation between the currently recognized gasterosteoids and syngnathoids in the 10th edition of Systema Naturae. Gasterosteids were placed in the Artedian Thoracici, while syngnathoids were divided into two groups, the Abdominales and the Branchiostegi. Pegasus was classified separately from the syngnathoids as a chondropterygian (Gill, 1884). In a major revision as part of the final edition of Systema Naturae, Linnaeus (1768) reclassified the syngnathoids Centriscus, Syngnathus and Pegasus together in the Amphibia Nantes, reflecting his erroneous belief that all these fishes possessed both lungs and gills, a contention which perplexed many of his contemporaries (Pietsch, 1995). The position of Fistularia and the gasterosteids remained unchanged in this edition of Systema Naturae. Linnaeus' systematic groupings of gasterosteoids and syngnathoids were retained for almost half a century, with only minor changes in taxonomic nomenclature during this time.

As part of his effort to classify fishes into natural groups on the basis of unique characters, Cuvier (1816) placed gasterosteiforms in three widely separated lineages and established two key new groups: the Lophobranches and 'Les Bouches en Flute'. Cuvier's Lophobranches united the pegasids, solenostomids and syngnathids, while 'Les Bouches en Flute' comprised the aulostomoids and centriscoids, marking the first time that these two lineages were closely associated. Cuvier \& Valenciennes (1829) tentatively placed the Gasterosteidae in a primarily scorpaeniform group, foreshadowing current ideas of scorpaeniform affinities based on molecular data.

The ideas of two American workers, Cope and Gill, had a broad influence on the thoughts of later researchers in gasterosteiform systematics. In establishing a filing system for use at the National Museum of Natural History, Washington DC, U.S.A. Gill (1872) was influenced in his ideas of the relationships of gasterosteiforms by Cope (1871). Gill's Lophobranchii contained only the Solenostomidae and the Syngnathidae [although Hippocampus was placed within its own family, the Hippocampidae, for reasons detailed by Gill (1896)], while his Hemibranchii was composed of the Gasterosteiformes, with presently recognized gasterosteoids and aulostomoids, and the Centrisciformes, containing only centriscoids [Fig. 2(a)]. Noting that a linear series of names is inadequate to express genetic relationships, he outlined the evolutionary lineage of fishes and depicted the Lophobranchii arising from the Hemibranchii. These ideas of gasterosteiform evolution followed Cope (1871), except for the placement of the Pegasidae, which was not included. Gill (1884) published a detailed analysis of the Hemibranchii, which contained all gasterosteiforms except syngnathids and solenostomids and argued that the Aulorhynchidae and Gasterosteidae were only slightly differentiated, even going as far as suggesting that they might appropriately be united into one family.

The landmark studies of Jungersen $(1908,1910)$ provided the first detailed accounts of the morphology of the Centriscidae and Macroramphosidae in 1908 and the Aulostomidae, Fistulariidae, Syngnathidae and Solenostomidae in 1910. In the first of these papers, he concluded that the Solenichthys (the Syngnathoidei less Pegasidae) was a natural group and that the Hemibranchii (Gasterosteoidei) and Pegasidae were not closely related to this group. He argued that several morphological characters 
(a)

Gill (1872, 1884)

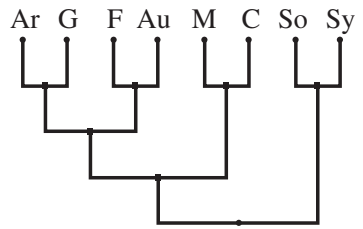

(c) $\operatorname{Berg}(1940)$

I Ar G F Au M C So Sy

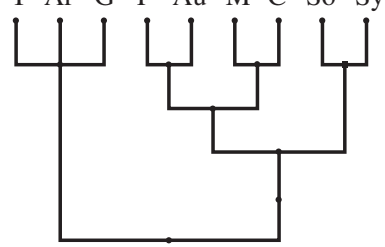

(e) $\operatorname{Orr}(1995)$

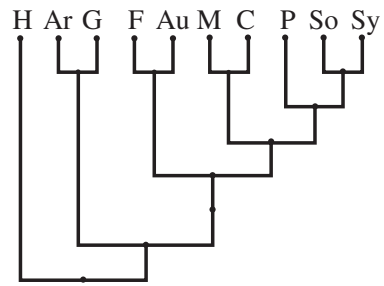

(g) Li et al. (2009)

I G C D M Au F Hi Sy Sy Sy Sy

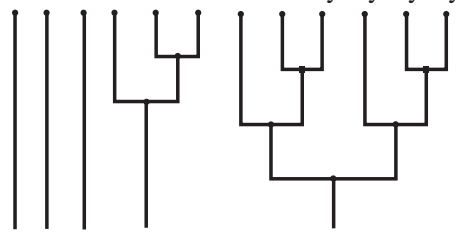

(b) Regan (1909)

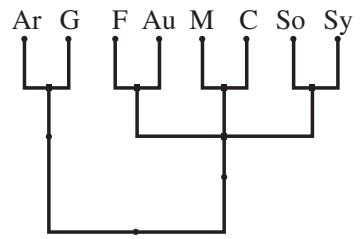

(d) Pietsch (1978)

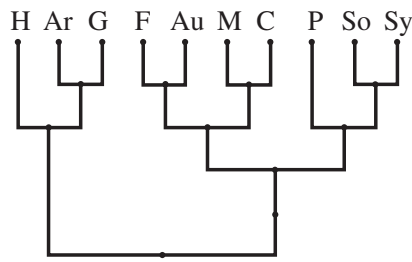

(f) Keivany \& Nelson (2006)

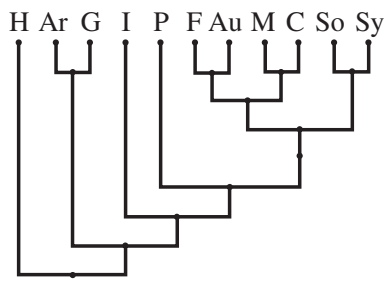

(h) Kawahara et al. (2008)

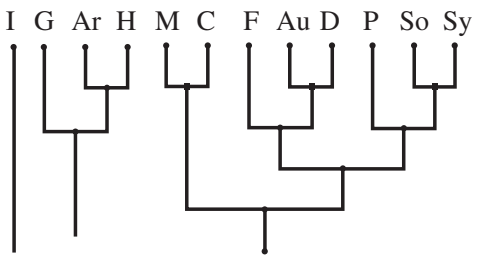

FIG. 2. Eight $(\mathrm{a}-\mathrm{h})$ morphological and molecular-based hypotheses on the interrelationships of families of gasterosteiforms. Ar, Aulorhynchidae; Au, Aulostomidae; C, Centriscidae; D, Dactylopteridae; F, Fistulariidae; G, Gasterosteidae; H, Hypoptychidae; Hi, Hippocampus; I, Indostomidae; M, Macroramphosidae; P, Pegasidae; So, Solenostomidae; Sy, Syngnathidae.

were 'found united in the whole community of forms' (his Solenichthys), placing centriscoids and aulostomoids together as a natural group and solenostomids and syngnathids as a separate but closely related lineage. He also concluded that gasterosteoids and pegasids belonged within scorpaeniforms, and were not closely related to syngnathoids, based on investigations that were never published (Jungersen, 1908, 1915). Regan (1909) was heavily influenced by the work of Jungersen (1908) and recognized monophyletic groups comparable to the Aulostomoidea, Centriscoidea 
and Syngnathoidea, though he did not specify their relationships to one another [Fig. 2(b)]. In later work, Regan (1913) suggested that gasterosteids were closely related to scorpaeniform fishes, reiterating the earlier conclusions of Cuvier \& Valenciennes (1829; see above).

In his influential classification, Berg (1940) listed the Gasterosteiformes in three separate orders [Fig. 2(c)]: the Gasterosteiformes, Syngnathiformes and Pegasiformes. The Gasterosteiformes contained the gasterosteoids as well as the Indostomidae, although as incertae sedis [the phylogenetic affinities of this family have remained controversial since its initial description (Prashad \& Mukerji, 1929)]. The Syngnathiformes included all syngnathoids, except the Pegasidae (which was placed in a separate order at the end of the classification), divided into two suborders following Jungersen (1910): the Aulostomoidei, with aulostomoids and centriscoids, and the Syngnathoidei, with solenostomids and syngnathids. Perhaps the most important higher level work in pre-cladistic systematic ichthyology was the classification of Greenwood et al. (1966), which summarized the state of knowledge of the evolutionary relationships of the main phyletic trends of teleosts. Following Berg's ideas of gasterosteiform relationships, Greenwood et al. (1966) tentatively brought all families together into a united Gasterosteiformes, indicating that the relationships of this group were 'still to be assessed'.

Although a description of the cladistic method, which emphasizes the pre-eminence of shared evolutionary novelties (i.e. synapomorphy) in revealing evolutionary relationships, was first published by Hennig (1950), the influence of this methodology was not felt in ichthyology until the English translation of his work became available in the U.S.A. (Hennig, 1966). The change in systematic rigour with the introduction of cladistic techniques was immense, as the methodology was applied to systematic studies of many taxa of fishes in the early 1970s. In the first cladistic treatment of the Gasterosteiformes, Pietsch (1978) firmly supported an expanded Gasterosteiformes, including the Pegasidae and adding the Hypoptychidae (the Indostomidae was not formally included in this analysis) [Fig. 2(d)]. Johnson \& Patterson (1993) added new characters to corroborate Pietsch's (1978) hypotheses of a monophyletic Gasterosteiformes, presented evidence to support monophyly of the Syngnatha (Pegasidae, Solenostomidae and Syngnathidae) and suggested that the Indostomidae should be placed within this group. The Gasterosteiformes were placed into a large group (Smegmamorpha), which included the Synbranchoidei, Mastacembeloidei, Elassoma, Mugilomorpha and Atherinomorpha, a relationship which has been called into question in subsequent studies (Springer \& Orrell, 2004).

Orr (1995) conducted a phylogenetic analysis of the Gasterosteiformes, primarily based on osteology, and examined the limits, monophyly and relationships of the 11 families of the order. His results supported the monophyly of the Gasterosteiformes and reinforced the monophyly of the traditional major family pairs within the order: the Gasterosteoidea, Aulostomoidea, Macroramphosoidea [=Centriscoidea of Keivany \& Nelson (2006)] and Syngnathoidea [Figs 1 and 2(e)]. The Pegasidae was found to be the sister group of the terminal clade containing the Solenostomidae and Syngnathidae. Orr (1995) excluded Indostomus from the Gasterosteiformes and suggested a sister group relationship between the Hypoptychidae and the order Gasterosteiformes [Figs 1 and 2(e)].

Understanding the limits and constituents of the taxonomic groups under investigation is critical to a phylogenetic analysis. The influence of taxonomic sampling can 
be seen in the morphological analysis of Keivany \& Nelson (2006), who compiled data of their own with the analyses of several previous morphological analyses in an analysis of all families recently considered to be members of the Gasterosteiformes. They assumed monophyly of the group (Johnson \& Patterson, 1993; Orr, 1995; Britz \& Johnson, 2002) and used the smegmamorphs of Johnson \& Patterson (1993) as outgroups. Their resulting tree [Fig. 2(f)] placed Indostomus as a basal syngnathoid followed by the Pegasidae, which is sister of the Syngnathoidea, the sister of the Aulostomoidea and Centriscoidea [=Macroramphosoidea of Orr (1995)].

Differences among recent morphological analyses of the group demonstrate the instability of the current understanding of gasterosteiform evolution. Orr's (1995) and Keivany \& Nelson's (2006) most parsimonious phylogenetic trees were weakest at the nodes of most interest in syngnathoid evolution, the position of the Pegasidae and relationship of the Aulostomoidea and Centriscidae. Outgroup choice and the representation of in-group taxa may have strong effects on the resolution of relationships within a group of interest. With few exceptions, differences in taxonomic representation among morphological and molecular analyses have produced incongruous results in studies of gasterosteiform families.

\section{MOLECULAR ANALYSES}

Two recurring results have been found in all higher level molecular studies published to date: (1) the paraphyly of the Gasterosteiformes and (2) the placement of the Gasterosteoidei together with the cottoid-zoarcoid lineage of Imamura \& Yabe (2002). As most higher level molecular studies have had a broad taxonomic focus, taxon sampling of traditional gasterosteiform members has been incomplete, making it difficult to evaluate the relationships of the group as a whole. Early analyses based on complete mitochondrial DNA genome sequences of gasterosteids, Hypoptychus and Indostomus consistently placed gasterosteids and Hypoptychus basal to the cottoid-zoarcoid lineage and positioned Indostomus within the Synbranchiformes (Miya et al., 2001, 2003, 2005).

As nuclear sequences have come to be integrated into molecular analyses, incongruencies between molecular and morphological analyses of gasterosteiform relationships have become more pronounced. Within an extensive acanthomorph data set, Chen et al. (2003) sampled the gasterosteoid Spinachia and the syngnathoids Aulostomus and Macroramphosus and analysed sequence data from two nuclear (28S rDNA and rhodopsin) and two mitochondrial genes (12S and $16 S$ rDNA). Spinachia was placed basally among a miscellaneous assortment of fishes, while Aulostomus and Macroramphosus were found to be closely related and situated in a wellsupported lineage together with Dactylopterus. The analysis of combined mtDNA ( $12 S$ and $16 S$ rDNA) and nDNA (28S rDNA, histone $\mathrm{H} 3$ and TMO-4c4) data sets by Smith \& Wheeler (2004) and Smith \& Craig (2007) consistently recovered a relationship of gasterosteoids with the cottoid-zoarcoid lineage of Imamura \& Yabe (2002). Although Aulostomus was the only syngnathoid sampled in these two studies, it was found to be distantly related to gasterosteoids, consistent with the earlier results of Chen et al. (2003). Dettai \& Lecointre (2005) added taxa and two portions of a novel nuclear locus [mixed lineage leukaemia-like gene (MLL)] to the data set of Chen et al. (2003). In all their analyses, the Gasterosteiformes was paraphyletic, 
and gasterosteoids were placed again at the base of a cottoid-zoarcoid clade distant from syngnathoids. Oddly, while their analysis of the MLL gene recovered a monophyletic Syngnathidae, their total-evidence phylogenetic analysis (including previously published rhodopsin, $28 S$ rDNA and mtDNA $12 S$ and $16 S$ rDNA data) placed Syngnathus in a clade distant from all other syngnathoids, including Hippocampus (Dettai \& Lecointre, 2005), a result that has not been found in any other study of syngnathoid phylogenetics.

Further emphasizing the contrast between molecular and morphological studies of gasterosteiforms, the supertree analysis of Li et al. (2009), which sampled four nuclear genes across a broad array of acanthomorphs, placed gasterosteiforms in five different clades [Fig. 2(g)]: indostomids among synbranchiforms, fistularids together with syngnathids, aulostomids and macroramphosids with dactylopterids, and centriscids in a polytomy among miscellaneous perciforms. In a separate tree, gasterosteoids were placed with the cottoid-zoarcoid lineage. With the exception of gasterosteoid and indostomid relationships, none of these ideas, particularly the paraphyly of syngnathoid superfamilies, are supported by morphological data.

In the most comprehensive molecular study of gasterosteiform relationships to date, Kawahara et al. (2008) used complete mitochondrial genome sequences of representatives of all gasterosteiform families (including the Solenostomidae for the first time). Kawahara et al. (2008) found the Gasterosteiformes to be paraphyletic, again recovering the Gasterosteoidei together with cottoids and zoarcoids. Indostomus was placed with the Synbranchiformes, and members of the Syngnathoidei were placed together with dactylopterids in a polytomy with percomorphs [Fig. 2(h)]. Kawahara et al. (2008) supported a sister group relationship between the Pegasidae and the Syngnathidae and Solenostomidae, as in Orr (1995) [but in contrast with Keivany \& Nelson (2006)], while the basal placement of the Centriscoidea by Kawahara et al. (2008), and the grouping of the Aulostomoidea with Dactylopterus (as the sister of Aulostomus) contrasted with both morphological analyses \{Orr, 1995; Keivany \& Nelson, 2006; though the relative position of these two superfamilies was admittedly only weakly supported in these earlier studies [Fig. 2(e), (f)]\}. In contrast to all previous morphological analyses, Kawahara et al. (2008) found that the Syngnathoidei was closely related to the Gobioidei.

If the Gasterosteiformes are paraphyletic and Indostomus is allied with the Synbranchiformes, what is the sister group of the Syngnathoidei and where is its systematic position? While the Gasterosteoidei appears to be related to the cottoid-zoarcoid lineage, the placement of the Syngnathoidei within the acanthomorph bush remains uncertain. Morphological analyses have provided no alternative to the hypothesis of a sister group relationship between the Gasterosteoidei and the Syngnathoidei, and the results of molecular analyses have been incongruent. Among molecular analyses, the Syngnathoidei (plus Dactylopteridae) was found to be monophyletic only by Kawahara et al. (2008). Although morphological characters may ultimately be discovered which support a sister group relationship among other acanthomorphs, it is probable that questions related to the origins of the group will require a broadened search for appropriate outgroups (Smith \& Craig, 2007). Molecular analyses of deep-level phylogenetic relationships may be susceptible to positively misleading evidence, but the ability to rapidly screen a broad diversity of distantly related taxa means that future studies on gasterosteiform relationships will heavily emphasize this form of data (Smith \& Craig, 2007). 


\section{FAMILY-LEVEL PHYLOGENETICS}

While higher level phylogenetic analyses have proven problematic for syngnathoids, the evolutionary relationships among members of the family Syngnathidae have been resolved with greater confidence. As outlined above, Linnaeus recognized syngnathids in his earliest classification of animals and described both seahorses and pipefishes in the first edition of Systema Naturae (Linnaeus, 1735). Following the descriptions of many new syngnathid species during the 18th and early 19th centuries, the first systematic description of the group was published by Kaup (1856), who considered the location and degree of development of the male brood pouch in dividing the family Syngnathidae into four subfamilies (Doryrhampinae, Nerophinae, Hippocampinae and Syngnathinae). Subsequent authors adopted this classification system (Duméril, 1870), and although several authors have used a different system of syngnathid classification (Kuiter, 2000; Nelson, 2006), these four subfamilies are still in common use today. Wilson \& Rouse (2010) have proposed a revision of syngnathid subfamilies based on the results of a mtDNA-based phylogeny.

Duncker $(1912,1915)$ was the first to recognize that syngnathids could be naturally partitioned into two major groups based on the location of the male brood pouch. His Gastrophori (literally, abdominal-bearing) and Urophori (tail-bearing) were further divided into six subfamilies [Kaup's (1856) four plus the Gastrotokeinae $=$ Syngnathoidinae and Solenognathinae, with three in both the Gastrophori and Urophori] according to the complexity of male brooding structures (Duncker, 1912). Unfortunately, Duncker's planned 'Synopsis of the Syngnathidae' was never published, and his rich collection of syngnathid fishes housed in the Natural History Museum, Hamburg, Germany was lost during the bombing of the city in 1939-45 (Thiel et al., 2009).

In the first explicitly phylogenetic analysis of syngnathid evolution, Herald (1959) used Duncker's $(1912,1915)$ system of classification to develop an evolutionary hypothesis on the origin and diversification of the group. According to Herald (1959), the Syngnathidae diverged early in its evolution into tail and trunk-brooding species. Following the development of a rudimentary form of male brooding in both these lineages, brood-pouch complexity evolved in parallel in the Gastrophori and Urophori, resulting in the fully enclosed pouch of the seahorse and the highly developed brooding structures found in some gastrophorine species. Herald (1959) suggested that the brooding structures of urophorine pipefish with partially enclosed brood pouches could be further subdivided into monophyletic lineages according to their method of closure (inverted, semi-inverted, overlapping and everted) and proposed a multistage model by which the fully enclosed pouch of the seahorse was derived from pipefish ancestors with an everted brooding structure.

C. Dawson was the most recent researcher to tackle family-level syngnathid relationships from a global perspective (Overstreet \& Poss, 1993). In revisions of North Atlantic (Dawson \& Vari, 1982), Indo-Pacific (Dawson, 1985) and Mediterranean syngnathids (Dawson, 1986), Dawson made major strides towards clarifying the taxonomy of the group, synonymizing many species that had been previously described on the basis of regional collections. Only 294 of the 558 nominal species of syngnathids are presently considered to be valid (Froese \& Pauly, 2010), and Dawson was responsible for the reclassification of 185 (>30\%) of these nominal taxa. Over 
a career spanning more than five decades, Dawson also described 37 new species of syngnathids, 36 of which are still recognized as valid (Froese \& Pauly, 2010).

In the first family-level molecular phylogenetic study of the Syngnathidae, Wilson et al. (2001) used a suite of three mtDNA markers to reconstruct the evolutionary history of the group. This study included 34 species distributed across 16 of the presently recognized 54 syngnathid genera, with a strong emphasis on the two most species-rich genera in the family, Hippocampus and Syngnathus. While the taxonomic sampling of this study was far from complete, these first molecular phylogenetic results provided several key insights into the evolution of the family. Wilson et al.'s (2001) study supported Duncker's (1912) morphologically based grouping of the Urophori and Gastrophori, indicating that trunk- and tail-brooding lineages diverged early in the evolution of the family, but suggested that several major pouch types within each of these lineages had independent evolutionary origins, challenging the phylogenetic model proposed by Herald (1959). This study also supported a close evolutionary relationship between Syngnathus pipefish and Hippocampus, contradicting Herald's (1959) theory on the origin of the seahorse brood pouch [though the limited taxonomic sampling of Wilson et al. (2001) did not permit a robust test of this hypothesis]. A recently published phylogenetic analysis of syngnathids has provided compelling evidence that trunk brooding may have been secondarily acquired in Syngnathoides biaculeatus (Bloch 1785) (Fig. 3; Wilson \& Rouse, 2010), making this species of particular interest in studies aimed at understanding the functional and morphological changes associated with the evolution of male pregnancy in this group.

Unfortunately, while the mtDNA-based molecular phylogeny of Wilson et al. (2001) provides strong support for the early divergence of the Urophori and the Gastrophori and supports the monophyly of several major in-group taxa, much of the backbone of the syngnathid phylogenetic tree remains poorly resolved, complicating efforts to fully understand the pattern of speciation and diversification in the group. Several follow-up studies have broadened the species sampling of this original phylogeny for the three mtDNA genes used in the original Wilson et al. (2001) analysis (Wilson et al., 2003; Wilson \& Rouse, 2010) and have addressed important questions related to the evolution of the family, but the timing of key evolutionary events during the early evolution of the Urophori remain unresolved. Further resolution of the syngnathid family tree will probably only be achieved with the use of nDNA loci, whose slower rate of evolution may be more appropriate for resolving deeper level divergences in this group. A major phylogenetic analysis of the Syngnathidae using both nDNA and mtDNA markers and including a much wider taxonomic sample of species is currently underway (H. Hamilton, pers. comm.) and is expected to provide higher resolution at the deeper nodes in the syngnathid phylogeny. The most up-to-date phylogenetic tree of the family Syngnathidae, based on mtDNA sequence data, is provided in Fig. 3.

\section{FOSSIL RECORDS}

All members of the Syngnathidae have a dermal skeleton composed of body plates, and this group is consequently relatively well represented in the marine fossil record (Fig. 4). The availability of a rich fossil record is an essential prerequisite for 


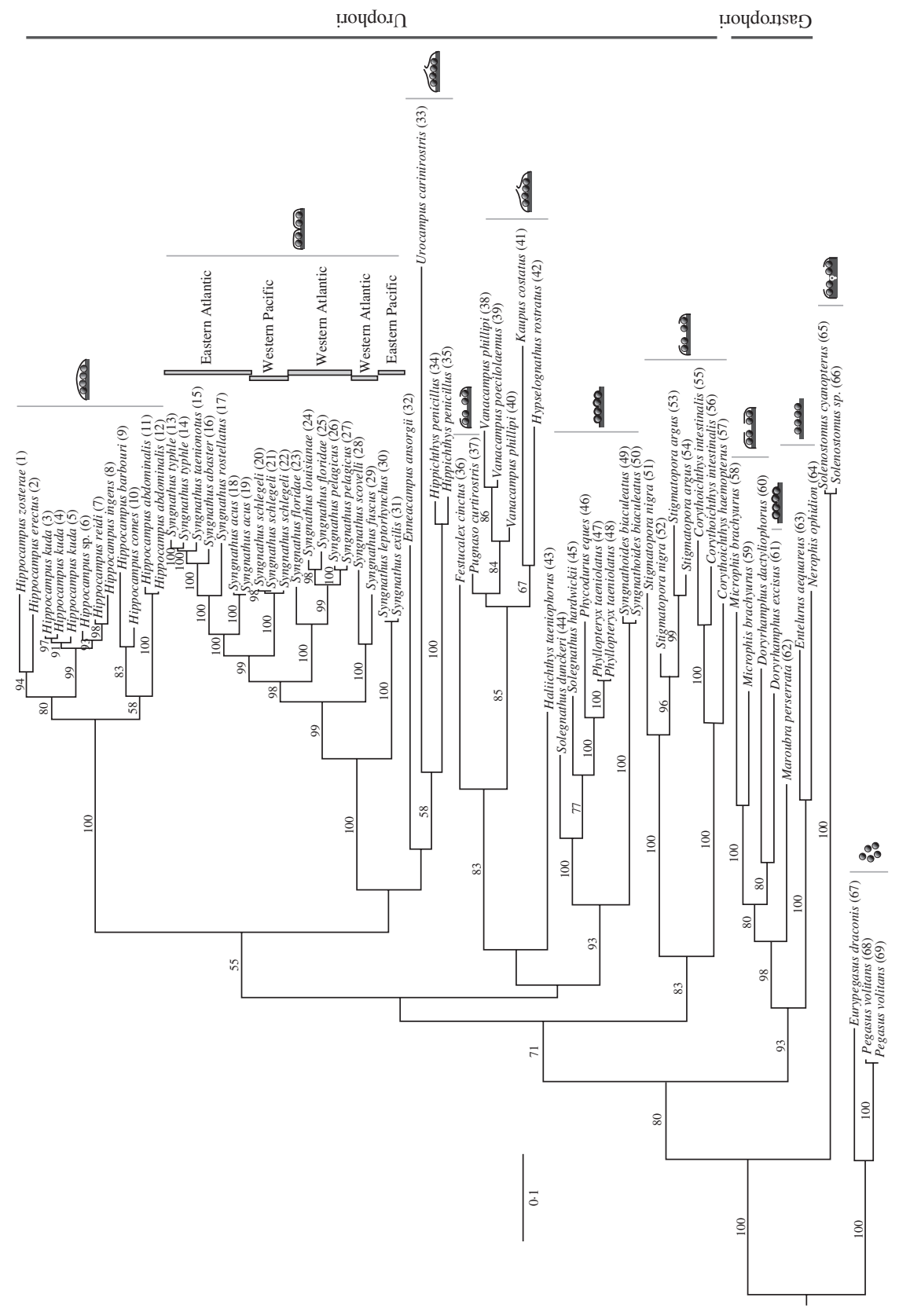


studies aimed at the evolutionary origins of a group and, together with molecular data, can provide a temporal framework in which to study both its origin and pattern of diversification.

Syngnathoid fossil finds are richest in the Mediterranean Sea and Black Sea regions, but large numbers of Oligocene and Miocene fossils have also been collected from Paratethys sites in central Europe (Fig. 4). In addition to this rich European fossil record, fossils of three syngnathid species have been collected from the Modelo and Puente formations of southern California (Fritzsche, 1980). Mirroring the confusion surrounding the higher level relationships among contemporary taxa, considerable debate has surrounded the taxonomic placement of many syngnathoid fossils. Many fossil species remain undescribed, and while the fossil species discussed here are believed to represent valid taxa, a comprehensive consideration of the more problematic gasterosteiform fossils awaits a detailed review.

The oldest syngnathoid fossils date from the early Eocene [48-50 million years before present (B.P.)], and the majority of these fossil taxa have been collected from the rich fossil beds of the Monte Bolca formation in northern Italy (Blot, 1980). Six fossil syngnathoids have been collected from Eocene deposits in this region, representing five distinct taxonomic lineages (Fig. 4). Species of the now extinct Ramphosidae, a family which has been suggested to be a sister group to the extant Pegasidae (Pietsch, 1978), have been collected from Eocene sites in Monte Bolca (Blot, 1980) and from a second locality in Jutland, Denmark (Nielsen, 1960). Three additional Monte Bolca fossils are believed to represent morphologically-distinct syngnathoid lineages, and Solenorhynchus elegans (Heckel 1853) and Calamostoma breviculum Agassiz 1833 are thought to be intermediate forms between the Solenostomidae and the Syngnathidae (Orr, 1995). The oldest syngnathid fossil is believed to be Prosolenostomus lessenii Blot 1980, a species that has been placed in the stem lineage of the Syngnathidae on the basis of its absence of dorsal and pelvic fins (Orr, 1995). While the age of Prosolenostomus indicates that the family Syngnathidae is at least 50 million years old, the high diversity of syngnathoid fossils found in Eocene deposits suggests that the family probably predates this period.

While the fossils collected from the Eocene deposits of Monte Bolca cannot be confidently assigned to an extant genus, more recent fossils have been partitioned to either the Urophori or the Gastrophori on the basis of their brooding structures. The genus Hipposyngnathus is the oldest gastrophorine lineage yet discovered and

FIG. 3. Maximum-likelihood molecular phylogenetic tree of the Syngnathidae, based on complete cytochrome $b$ and partial $12 S$ rDNA and $16 S$ rDNA sequence data, with individual partitions for each of the mtDNA data sets and a common GTR + I + G model of evolution. Specimen numbers indicated in parentheses (Table SII for a full list of sequence accessions). Tree reliability was estimated using bootstrap resampling (200 replicates; bootstrap values $>50 \%$ indicated). Brood-pouch cross-sections illustrate pouch variation [@, fully enclosed pouch; pouch (semi); rudimentary pouch with plates and skin-folds;

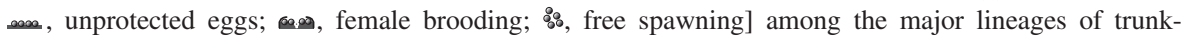
(Gastrophori) and tail-brooding (Urophori) species. The trunk-brooding Syngnathoides biaculeatus has recently been shown to cluster together with urophorine species, suggesting that trunk brooding has evolved independently in this lineage (Wilson \& Rouse, 2010). Note the low level of support for the backbone of the syngnathid tree. Methodological details for this analysis are provided in Appendix SI. 


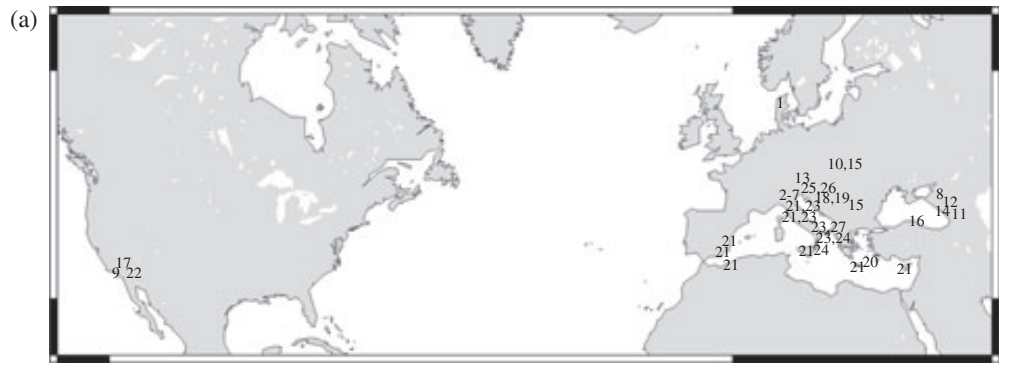

(b)

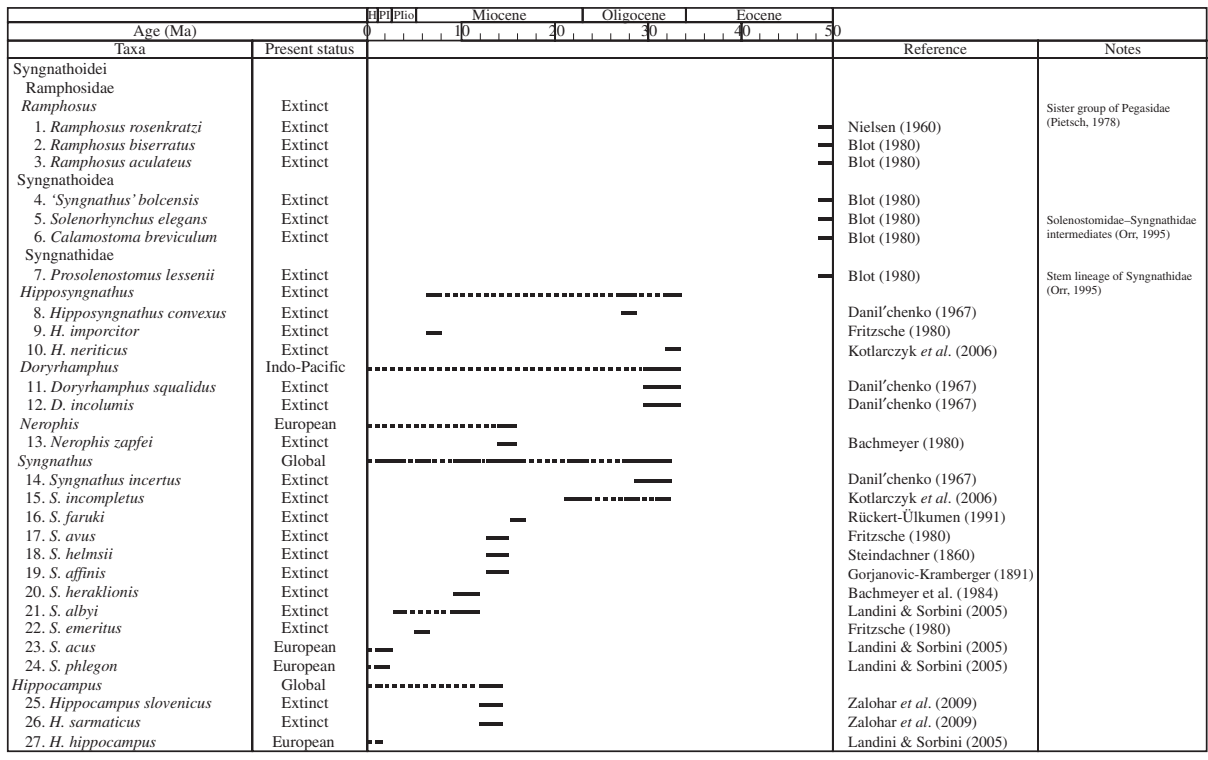

FIG. 4. The syngnathoid fossil record. (a) A summary of published reports of syngnathoid fossils, indicating (a) the locality of the fossil description (above) and (b) the approximate age of the fossil deposits based on data reported in the original publications. __ described fossils; ......... presumed presence based on more recent fossil finds and the existence of contemporary taxa (Landini \& Sorbini, 2005).

represents an extinct lineage of pipefishes that persisted from the early Oligocene until the Miocene (Fig. 4). Three fossil species have been described from this genus, two from early Oligocene deposits in the Caucasus and Carpathian basins [Hipposyngnathus convexus Danil'chenko 1960 and Hipposyngnathus neriticus Jerzmañska 1968 (Danil'chenko, 1967; Kotlarczyk et al., 2006)] and one from Miocene deposits of southern California (Hipposyngnathus imporcitor Fritzsche 1980), indicating that this genus achieved a wide distribution during its existence.

The earliest gastrophorine fossils with clear affinities for extant genera are the early Oligocene Dunckerocampus incolumis Danil'chenko 1967 and Dunckerocampus squalidus Danil'chenko 1967 from the Caucasus (Danil'chenko, 1967) and the Miocene Nerophis zapfei Bachmeyer 1980 (Bachmayer, 1980) of eastern Austria, indicating the extended evolutionary history of these two lineages (Fig. 4). The modern Nerophis is found in the temperate coastal habitats along the European coastline; Dunckerocampus spp. are currently restricted to the Indo-West Pacific Ocean (Froese \& Pauly, 2010). 
Both Hippocampus and Syngnathus are well represented in the urophorine fossil record. Syngnathus has the richest fossil record of any extant syngnathid genus, and 11 fossil Syngnathus species are currently recognized. The oldest Syngnathus fossils date from the early Oligocene (Danil'chenko, 1967; Kotlarczyk et al., 2006), and the genus has an almost uninterrupted fossil record from this period until the present day (Fig. 4). The highest diversity of Syngnathus fossils has been found in the pre-Messinian deposits of the Miocene Mediterranean Sea, though the existence of Syngnathus avus Jordan \& Gilbert 1919 in southern Californian formations indicates that the genus has been present on the Pacific Coast of North America for at least 15 million years. While at least four Syngnathus species were present in the Miocene Mediterranean Sea (15 M B.P.), subsequent deposits are dominated by a single widespread species (Syngnathus albyi Sauvage 1870), which has been collected from many sites around the modern Mediterranean Sea basin (Landini \& Sorbini, 2005). Syngnathus albyi appears to have persisted through the Messinian salinity crisis in the Mediterranean Sea (c. $6 \mathrm{M}$ B.P.), but is replaced in more recent Pliocene and Pleistocene deposits by the modern Syngnathus acus L. 1758 (Fig. 4).

While a Pleistocene fossil of the extant Hippocampus hippocampus (L. 1758) was long the only known representative of this genus in the fossil record (Landini \& Sorbini, 2005), two Miocene fossils have been described from Sarmatian deposits in Slovenia [Hippocampus sarmaticus Zalohar, Hitij \& Kriznar 2009 and Syngnathus slovenicus Zalohar, Hitij \& Kriznar (Zalohar et al., 2009)], considerably extending the age of this lineage. The two Slovenian seahorse fossils are clearly distinct, with $H$. sarmaticus showing affinities for the modern Hippocampus trimaculatus Leach 1814 and $H$. slovenicus bearing a resemblance to contemporary pygmy seahorses (Zalohar et al., 2009). Again, major morphological differences between these two fossils suggest that the seahorse lineage predates the Miocene, consistent with recent molecular clock reconstructions of the group (Teske \& Beheregaray, 2009).

\section{INTRAGENERIC RELATIONSHIPS}

Both phylogenetic and phylogeographic studies have heavily emphasized the evolution of seahorses (genus Hippocampus) and Syngnathus pipefishes, providing insights into the biogeography of these two genera. A 2004 issue of Molecular Phylogenetics and Evolution saw the publication of back-to-back articles on the evolutionary relationships of the seahorse. The first, by Casey et al. (2004), analysed full-length cytochrome $b$ sequences in a sample of 22 seahorse species, including multiple representatives of each species sampled. A second study by Teske et al. (2004) supplemented the Casey et al. (2004) cytochrome $b$ data set with $16 S$ rDNA sequence data and two nuclear genes (RP1 and aldolase) and included a total of 30 seahorse species. The analysis of Teske et al. (2004) produced a highly resolved phylogeny of the seahorse genus and provided important insights into the evolutionary history of the group.

On the basis of the placement of the Australian Hippocampus breviceps Peters 1869 and Australian and New Zealand Hippocampus abdominalis Lesson 1827 at the base of the seahorse phylogeny and the south-west Pacific Ocean distribution of several outgroup species, Teske et al. (2004) hypothesized an Australian origin for the genus Hippocampus. The main group of seahorses falls into three major clades, two 
with Indo-Pacific affinities and one with a circumglobal distribution, a lineage which is thought to have had its origin following the colonization of the Atlantic Ocean (Teske et al., 2004). This lineage subsequently recolonized the Indo-West Pacific Ocean, giving rise to a species-rich group including the widespread Hippocampus kuda Bleeker 1852. The alternative hypothesis, that Atlantic Ocean seahorse species are the descendents of repeated colonizations of this region, however, could not be statistically rejected. Subsequent biogeographic analyses indicate that long-distance dispersal events have placed an important role in the origin of new seahorse lineages in the Indo-West Pacific (Teske et al., 2005) and Atlantic Oceans (Teske et al., 2007).

The original family-level phylogeny of the Syngnathidae included 11 species of Syngnathus pipefishes from Europe, Asia and North America (Wilson et al., 2001). While the relationships among Syngnathus pipefishes were poorly resolved using the pruned data set published in the original paper (third codons of cytochrome $b$ were removed due to mutational saturation at high genetic distances), the full data set used for the updated family-level phylogeny published here provides a high degree of resolution within Syngnathus, with strong support for all major nodes in the Syngnathus phylogeny (Fig. 3).

Similar to the results observed for Hippocampus, there is clear geographical structure in Syngnathus biogeography. The most basal lineages in the Syngnathus phylogeny are restricted to the Pacific coast of North America [Syngnathus exilis (Osburn \& Nichols 1916) and Syngnathus leptorhynchus Girard 1854], and the remainder of the phylogeny is divided into three major clades, a widespread Atlantic coast group [Syngnathus fuscus Storer 1839 and Syngnathus scovelli (Everman \& Kendall 1896)], a second clade containing Atlantic coast and Caribbean species, and a third clade containing the western Pacific Syngnathus schlegeli Kaup 1856 and a monophyletic clade of European pipefishes (Fig. 3). The close phylogenetic relationships between clades on east and west coasts of North America and Eurasia suggest that interoceanic dispersal may be relatively common in Syngnathus, a pattern which mirrors that detected in Hippocampus. Interestingly, given that the oldest Syngnathus fossils are from Oligocene sites in eastern Europe, the present-day phylogeny of the genus appears to reflect the consequences of extensive speciation and extinction during the evolution of the group.

\section{PHYLOGEOGRAPHY}

Recent publications concerning the evolution and origin of syngnathids have been dominated by phylogeographic investigations of individual species. Here again, studies have focused almost exclusively on Hippocampus and Syngnathus (Table SI), providing an excellent data set in which to identify general patterns in the contemporary phylogeography of these two genera.

Despite differences in the spatial scales (from $10^{1}$ to $10^{4} \mathrm{~km}$ ), the number of individuals screened (from $<10$ to $>300$ ) and the markers used (mtDNA and nDNA sequence data, microsatellites and allozymes), the majority of studies on both seahorses and pipefishes have found moderate-to-high genetic diversity and strong phylogeographic structure, consistent with large effective population sizes and low dispersal potential of syngnathid species. Studies conducted on northern-hemisphere 
temperate water species have typically found evidence of recent population expansions, consistent with the colonization of northern habitats following the end of the last glacial maximum (c. $20 \mathrm{k}$ B.P.). The large number of phylogeographic studies published over the past decade cannot be reviewed in detail here (see Table SI for a list of published studies), but a number of case studies serve to illustrate how phylogeographic analyses have contributed to a greater understanding of syngnathid evolution.

\section{PANMIXIA IN POPULATIONS OF H. ABDOMINALIS}

In contrast to the majority of phylogeographic studies on syngnathid species, which have found evidence of strong population structuring in both seahorses and pipefishes, recent investigations by Armstrong (2001) and Nickel (2009) found a surprising lack of phylogeographic structure in New Zealand and Australian populations of $H$. abdominalis. Armstrong (2001) used a combination of morphological characters, mtDNA sequence data and allozymes to investigate the hypothesis that Australian and New Zealand populations of $H$. abdominalis represent distinct species (Kuiter, 2001). While morphological variation in H. abdominalis was high, the majority of this variation was found within populations, with no diagnostic differences between the putative species. Allozyme markers could not distinguish between New Zealand and Australian populations, though some evidence of geographic structure was detected in mtDNA data, where the majority of New Zealand individuals formed a monophyletic clade. Armstrong (2001) rejected the hypothesis that H. abdominalis represented more than a single species, though molecular data do appear to indicate that populations in these two regions may be in the early stages of divergence.

In a study aimed at investigating the conservation status of New Zealand populations of H. abdominalis, Nickel (2009) used multiple mtDNA markers and nuclear microsatellites to investigate the phylogeographic structure of a large number of populations on both the north and south islands of the country. Although Nickel (2009) observed a remarkable range of morphological and colour variation among individuals [consistent with the results of Armstrong (2001)], and high genetic diversity at both mtDNA and microsatellite loci, no evidence of phylogeographic structure was found. The distribution of mtDNA haplotypes was found to be consistent with a recent population expansion, leading Nickel (2009) to suggest that New Zealand may have been colonized relatively recently by Australian seahorses, a situation which could help to explain the lack of population structure observed in the region. The application of molecular dating to these data should permit a robust test of timing of the colonization of New Zealand by H. abdominalis.

\section{IDENTIFYING PHYLOGEOGRAPHIC BREAKS: THE IMPORTANCE OF SCALE}

The broad distributions of many syngnathids make this group particularly well suited for studying the population genetic consequences of environmental variation across time and space. The Pacific Coast pipefish S. leptorhynchus is one of the most widespread pipefish species and is distributed across almost $4000 \mathrm{~km}$ of coastline between the Alexander Archipelago, Alaska, U.S.A. and Baja California, 
Mexico. Morphological variation in S. leptorhynchus is high, a finding which has led some researchers to suggest that it may actually comprise more than a single species (Herald, 1941). On the basis of meristic variation, Herald (1941) suggested that $S$. leptorhynchus could be divided into a northern and southern species, with a biogeographic boundary near Point Conception in southern California.

Two recent studies have used molecular markers to study the Pacific Coast phylogeography of S. leptorhynchus (Louie, 2003; Wilson, 2006). While both studies covered the same geographic range, Louie (2003) used a high-density sampling strategy, surveying almost 400 individuals sampled from 29 coastal sites, while Wilson (2006) sampled larger numbers of individuals from four collection localities. Both studies found evidence of the post-glacial colonization of northern sites following the end of the last glacial cycle and detected evidence of a phylogeographic break between sites in the north-west Pacific Ocean and those farther south. Interestingly, while the phylogeographic break identified by Wilson (2006) was found between central Oregon and California, U.S.A., the mtDNA data of Louie (2003) suggested that this break was located nearly $500 \mathrm{~km}$ farther north, in northern Washington. While the statistical approaches used in these two studies were not identical, differences in their conclusions can be largely attributed to differences in their sampling strategies, illustrating the potential challenges inherent in interpreting the results of molecular analyses.

\section{COMPARATIVE PHYLOGEOGRAPHY OF SEAHORSES: NEW INSIGHTS VIA SPECIES-LEVEL COMPARISONS}

In what is undoubtedly the most impressive analysis of comparative phylogeographic structure in a group of syngnathids, Lourie et al. (2005) investigated the phylogeographic structure of four south-east Asian seahorse species inhabiting a region dominated by the presence of the Sunda Shelf, a large shallow sea which has been repeatedly exposed as land during the sea-level reductions associated with Pleistocene glacial cycles. Lourie et al. (2005) sampled widely (11-29 populations of each species) and, most importantly, used the same fragment of the mtDNA cytochrome $b$ gene for all species, facilitating the direct comparison of phylogeographic structure. Differences in the contemporary population genetic structure of the four Hippocampus species could be directly attributed to species-specific habitat and ecological differences. While genetic diversity was high in all species, population genetic structuring was especially pronounced in Hippocampus barbouri Jordan \& Richardson 1905 and $H$. kuda, two shallow-water species, while phylogeographic structure was more modest in the deep-water Hippocampus spinosissimus Weber 1913 and H. trimaculatus (Lourie et al., 2005).

Differences in phylogeographic structure among these species appear to reflect differences in their relative dispersal abilities. While both deep-water species appear to have colonized the Sunda Shelf since its most recent flooding (c. 15 k B.P.), $H$. barbouri has not yet spread into the region, and the large number of private haplotypes found in shelf populations of $H$. kuda suggest that these lineages are derived from a refugial population. In an innovative use of haplotype frequency data, Lourie et al. (2005) inferred dispersal potential of the four study species by examining the geographic distribution of individual haplotypes, an approach which serves as an indirect estimate of relative dispersal. The scale of the Lourie et al. (2005) investigation exceeds that of most previously published phylogeographic studies on the 
group [Woodall (2009) provides a comparably impressive data set for European seahorses], and such comparative studies offer one of the best means by which the factors contributing to population and species-level divergence can be identified.

\section{CONCLUSIONS}

Researchers have long been interested in the evolutionary relationships among syngnathids, and the past several decades have provided new insights into the evolution of the group. The application of molecular methods has proven particularly effective in illuminating more recent evolutionary events, while both molecular and morphological analyses have failed to provide a well-resolved model of deeper level relationships, complicating efforts to understand the evolutionary origins of the family Syngnathidae. Although the sister group relationship of the Solenostomidae and the Syngnathidae appears to be robust, the relationships among other major groups within the order Gasterosteiformes remain poorly understood. Comparative ontogenetic studies may help to complement morphological analyses based on adult specimens, and a broadened analysis using molecular methods may provide an evolutionary hypothesis that could be corroborated with further morphological investigations.

While the large number of recent studies on syngnathid phylogeography and phylogenetics (and on many other aspects of syngnathid biology) have clarified several aspects of syngnathid evolution, most of these studies have been restricted to the two most species-rich genera of the family, seahorses (genus Hippocampus), and pipefishes of the genus Syngnathus. Although these publications have been prompted in part by considerable conservation interest in seahorse species (Foster \& Vincent, 2004), they tend to overlook the majority of morphological and ecological variation found in the rest of the family. As many syngnathid species inhabit the same sensitive environments inhabited by seahorses, they offer potentially useful comparative systems in which to investigate how ecological variation influences species susceptibility to habitat degradation. At the same time, a wider focus on the diversity of forms found in this family promises to provide a deeper understanding of the evolutionary pressures which have influenced its diversification.

Many thanks to T. W. Pietsch and D. E. Stevenson for discussions on many of the topics covered here. A particular thanks go to P. Armstrong, H. Hamilton, J. Nickel, N. Wilson and L. Woodall for providing access to unpublished data and thesis work cited in this review, and to I. Ahnesjö for editing this special syngnathid issue of the Journal of Fish Biology. Many of the out-of-print references cited here were provided from digital versions of the original publications prepared by the Biodiversity Heritage Library (http://www.biodiversitylibrary.org/), an important taxonomic resource for both living and fossil fishes.

\section{SUPPORTING INFORMATION}

Additional Supporting Information may be found in the online version of this article:

APPENDIX SI. Methodological details for phylogenetic reconstruction. 
TABLE SI. Syngnathid phylogeography, recent studies. Genetic markers: Microsats (Microsatellites), mtDNA (mitochondrial DNA), cyt $b$ (cytochrome $b$ ), COI (cytochrome oxidase subunit I), CR (control region).

TABLE SII. GenBank accession numbers for specimens included in phylogenetic analysis (Fig. 3).

\section{APPENDIX SII. Supplementary References.}

Please note: Wiley-Blackwell are not responsible for the content or functionality of any supporting materials supplied by the authors. Any queries (other than missing material) should be directed to the corresponding author for the article.

\section{References}

Armstrong, P. (2001). Genetic and morphological variation in pot-bellied seahorses (Hippocampus abdominalis): is there evidence for two species? BSc (Hons) Thesis, School of Aquaculture, University of Tasmania, Australia.

Bachmayer, F. (1980). Eine fossile Schlangennadel (Syngnathidae) aus dem Leithakalk (Badenien) von St. Margarethen, Burgenland (Österreich). Annalen des Naturhistorischen Museums Wien 83, 29-33.

Berg, L. S. (1940). Classification of fishes, both recent and fossil. Trudy Instituta Zoologii/ Akademiia Nauk, Azerbaidzhanskkoi SSR 5, 87-517. [English translation, 1947].

Berglund, A. \& Rosenqvist, G. (2003). Sex role reversal in pipefish. Advances in the Study of Behavior 32, 131-167.

Blot, J. (1980). La faune ichthyologique des gisements du Monte Bolca (Province de Verone, Italie). Bulletin du Museum d'Histoire Naturelle de Paris 4, 339-396.

Britz, R. \& Johnson, G. D. (2002). "Paradox lost": skeletal ontology of Indostomus paradoxus and its significance for the phylogenetic relationships of Indostomidae (Teleostei, Gasterosteiformes). American Museum Novitates 3383, 1-44.

Casey, S. P., Hall, H. J., Stanley, H. F. \& Vincent, A. C. (2004). The origin and evolution of seahorses (genus Hippocampus): a phylogenetic study using the cytochrome b gene of mitochondrial DNA. Molecular Phylogenetics and Evolution 30, 261-272.

Chen, W. J., Bonillo, C. \& Lecointre, G. (2003). Repeatability of clades as a criterion of reliability: a case study for molecular phylogeny of Acanthomorpha (Teleostei) with larger number of taxa. Molecular Phylogenetics and Evolution 26, 262-288.

Clutton-Brock, T. H. \& Vincent, A. C. (1991). Sexual selection and the potential reproductive rates of males and females. Nature (London) 351, 58-60.

Cope, E. D. (1871). Observations on the systematic relations of the fishes. American Naturalist 5, 579-593.

Cuvier, G. (1816). La règne animal distribué d'après son organisation, pur servir de base à l'histoire naturelle des animaux et d'introduction à l'anatomie compare. Paris: Chez Déterville.

Cuvier, G. \& Valenciennes, A. (1829). Histoire Naturelle des Poissons. Paris-Strasbourg: Chez F. G. Levrault.

Danil'chenko, P. G. (1967). Bony fishes of the Maikop deposits of the Caucasus. Transactions of the Paleontological Institute of the Academy of Sciences of the USSR 78, 1-208.

Dawson, C. E. (1985). Indo-pacific Pipefishes (Red Sea to the Americas). Ocean Springs, MS: Gulf Coast Research Laboratory.

Dawson, C. E. (1986). Syngnathidae. In Fishes of the North-eastern Atlantic and the Mediterranean (Whitehead, P. J. P., Bauchot, M. L., Hereau, J. C., Nielsen, J. \& Tortonese, E., eds), pp. 628-639. Paris: UNESCO.

Dawson, C. E. \& Vari, R. P. (1982). Fishes of the Western North Atlantic, Part Eight - Family Syngnathidae. New Haven, CT: Sears Foundation for Marine Research, Yale University.

Dettai, A. \& Lecointre, G. (2005). Further support for the clades obtained by multiple molecular phylogenies in the acanthomorph bush. Comptes Rendus Biologies 328, 674-689. 
Duméril, A. (1870). Histoire Naturelle des Poissons ou Ichthyologie Générale. Paris: Libraire Encyclopedique de Boret.

Duncker, G. (1912). Die Gattungen der Syngnathidae. Mitteilungen aus dem Naturhistorischen Museum in Hamburg 29, 219-240.

Duncker, G. (1915). Revision der Syngnathidae. Mitteilungen aus dem Hamburgischen Zoologischen Museum und Institut 32, 9-120.

Foster, S. J. \& Vincent, A. C. J. (2004). Life history and ecology of seahorses: implications for conservation and management. Journal of Fish Biology 65, 1-61.

Fritzsche, R. A. (1980). Revision of the eastern Pacific Syngnathidae (Pisces: Syngnathiformes), including both recent and fossil forms. Proceedings of the California Academy of Sciences 42, 181-227.

Gill, T. (1872). Arrangement of the families of fishes, or classes Pisces, Marsipobranchii, and Leptocardii. Smithsonian Miscellaneous Collections 247, 1-49.

Gill, T. (1884). On the mutual relations of the hemibranchiate fishes. Proceedings of the Academy of Natural Sciences of Philadelphia 36, 154-166.

Gill, T. H. (1896). The differential characters of the syngnathid and hippocampid fishes. Proceedings of the U.S. National Museum 18, 153-159.

Gorjanovic-Kramberger, G. (1891). Collectae Palaeoichthyologicae, Part II. Rad Jugoslavenske akademije znanosti i umjetnosti 106, 1-73.

Greenwood, P. H., Rosen, D. E., Weitzman, S. H. \& Myers, G. S. (1966). Phyletic studies of teleostean fishes with a provisional classification of living forms. Bulletin of the American Museum of Natural History 131, 339-455.

Hennig, W. (1950). Grundzüge einer Theorie der phylogenetischen Systematik. Berlin: Deutscher Zentralverlag.

Hennig, W. (1966). Phylogenetic Systematics. Urbana, IL: University of Illinois Press.

Herald, E. S. (1941). A systematic analysis of variation in the western American pipefish, Syngnathus californiensis. Stanford Ichthyological Bulletin 2, 49-73.

Herald, E. S. (1959). From pipefish to seahorse - a study of phylogenetic relationships. Proceedings of the California Academy of Sciences 29, 465-473.

Imamura, H. \& Yabe, M. (2002). Demise of the Scorpaeniformes (Actinopterygii: Percomorpha): an alternative phylogenetic hypothesis. Bulletin of Fisheries Sciences, Hokkaido University 53, 107-128.

Johnson, D. G. \& Patterson, C. (1993). Percomorph phylogeny: a survey of acanthomorphs and a new proposal. Bulletin of Marine Science 52, 554-626.

Jones, A. G., Rosenqvist, G., Berglund, A. \& Avise, J. C. (2005). The measurement of sexual selection using Bateman's principles: an experimental test in the sex-role-reversed pipefish Syngnathus typhle. Integrative and Comparative Biology 45, 874-884.

Jungersen, H. F. E. (1908). Ichthyotomical contributions I. The structure of the genera Amphisile and Centriscus. Memoires de l'Academie Royale des Sciences et des Lettres de Danemark, Copenhague, 7eme serie, Section de Sciences 6, 41-109.

Jungersen, H. F. E. (1910). Ichthyotomical contributions II. The structure of the Aulostomidae, Syngnathidae and Solenostomidae. Memoires de l'Academie Royale des Sciences et des Lettres de Danemark, Copenhague, 7eme serie, Section de Sciences 8, 269-363.

Jungersen, H. F. E. (1915). Some facts regarding the anatomy of the genus Pegasus. Reports of the 84th Meeting of the British Association for the Advancement of Science 1914, Transactions Section D 6, 420-422.

Kaup, J. J. (1856). Catalogue of Lophobranchiate Fish in the Collections of the British Museum. London: Taylor \& Francis.

Kawahara, R., Miya, M., Mabuchi, K., Lavoue, S., Inoue, J. G., Satoh, T. P., Kawaguchi, A. \& Nishida, M. (2008). Interrelationships of the 11 gasterosteiform families (sticklebacks, pipefishes, and their relatives): a new perspective based on whole mitogenome sequences from 75 higher teleosts. Molecular Phylogenetics and Evolution 46, $224-236$.

Keivany, Y. \& Nelson, J. S. (2006). Interrelationships of Gasterosteiformes (Actinopterygii, Percomorpha). Journal of Ichthyology 46, S84-S96.

Kotlarczyk, J., Jerzmanska, A., Swidnicka, E. \& Wiszniowska, T. (2006). A framework of ichthyofaunal ecostratigraphy of the Oligocene-Early Miocene strata of the Polish Outer Carpathian basin. Annales Societatis Geologorum Poloniae 76, 1-111. 
Kuiter, R. H. (2000). Seahorses, Pipefishes and Their Relatives. Chorleywood: TMC Publishing.

Kuiter, R. H. (2001). Revision of the Australian species of the genus Hippocampus (Syngnathiformes: Syngnathidae) with descriptions of nine new species. Records of the Australian Museum 53, 293-340.

Kvarnemo, C. \& Ahnesjö, I. (2002). Operational sex ratios and mating competition. In Sex Ratio Handbook (Hardy, I., ed.), pp. 366-382. Cambridge: Cambridge University Press.

Landini, W. \& Sorbini, C. (2005). Evolutionary dynamics in the fish faunas of the Mediterranean basin during the Plio-Pleistocene. Quaternary International 140, 64-89.

Li, B., Dettai, A., Cruaud, C., Couloux, A., Desoutter-Meniger, M. \& Lecointre, G. (2009). RNF213, a new nuclear marker for acanthomorph phylogeny. Molecular Phylogenetics and Evolution 50, 345-363.

Linnaeus, C. (1735). Systema Naturae, Sive Regna Tria Naturae, Systematice Proposita per Classes, Ordines, Genera, \& Species. Leiden: Lugduni Batavorum.

Linnaeus, C. (1758). Systema Naturae per Regna Tria Naturae, Secundum Classes, Ordines, Genera, Species, cum Characteribus, Differentiis, Synonymis, Locis. Stockholm: L. Salvii.

Linnaeus, C. (1768). Systema Naturae per Regna Tria Naturae, Secundum Classes, Ordines, Genera, Species, cum Characteribus, Differentiis, Synonymis Locis. Stockholm: L. Salvii.

Louie, K. D. (2003). Genetic structure and phylogeography of four eastern Pacific estuarine species, with an emphasis on eelgrass dependent taxa. PhD Thesis, University of California at Los Angeles, Los Angeles, CA, USA.

Lourie, S. A., Green, D. M. \& Vincent, A. C. J. (2005). Dispersal, habitat differences, and comparative phylogeography of Southeast Asian seahorses (Syngnathidae: Hippocampus). Molecular Ecology 14, 1073-1094.

Miya, M., Kawaguchi, A. \& Nishida, M. (2001). Mitogenomic exploration of higher teleostean phylogenies: a case study for moderate-scale evolutionary genomics with 38 newly determined complete mitochondrial DNA sequences. Molecular Biology and Evolution 18, 1993-2009.

Miya, M., Takeshima, H., Endo, H., Ishiguro, N. B., Inoue, J. G., Mukai, T., Satoh, T. P., Yamaguchi, M., Kawaguchi, A., Mabuchi, K., Shirai, S. M. \& Nishida, M. (2003). Major patterns of higher teleostean phylogenies: a new perspective based on 100 complete mitochondrial DNA sequences. Molecular Phylogenetics and Evolution 26, $121-138$.

Miya, M., Satoh, T. R. \& Nishida, M. (2005). The phylogenetic position of toadfishes (order Batrachoidiformes) in the higher ray-finned fish as inferred from partitioned Bayesian analysis of 102 whole mitochondrial genome sequences. Biological Journal of the Linnean Society 85, 289-306.

Nelson, J. S. (2006). Fishes of the World. Hoboken, NJ: John Wiley \& Sons.

Nickel, J. E. (2009). The diversity of Hippocampus abdominalis in New Zealand. PhD Thesis, University of Waikato, New Zealand.

Nielsen, E. (1960). A new Eocene teleost from Denmark. Meddelelser fra Dansk Geologisk Forening 14, 247-252.

Orr, J. W. (1995). Phylogenetic relationships of Gasterosteiform fishes (Teleostei: Acanthomorpha). PhD Thesis, University of Washington, Seattle, WA, USA.

Overstreet, R. M. \& Poss, S. G. (1993). Charles Eric "Chuck" Dawson 1922-1993. Copeia 1993, 921-925.

Pietsch, T. W. (1978). Evolutionary relationships of the sea moths (Teleostei: Pegasidae) with a classification of Gasterosteiform families. Copeia 1978, 517-529.

Pietsch, T. W. (Ed.) (1995). Historical Portrait of the Progress of Ichthyology From its Origin to Our Own Time (translated from G. Cuvier's original by A. J. Simpson). Baltimore, MD: Johns Hopkins University Press.

Prashad, B. \& Mukerji, D. D. (1929). The fish of the Indawgyi Lake and the streams of the Myitkyina District (Upper Burma). Records of the Indian Museum (Calcutta) 31, $161-223$.

Regan, C. T. (1909). The classification of teleostean fishes. Annals and Magazine of Natural History, Series 8 3, 75-86. 
Regan, C. T. (1913). The osteology and classification of the teleostean fishes of the order Scleroparei. Annals and Magazine of Natural History, Series 8 11, 169-184.

Rückert-Ülkümen, N. (1991). Fossile fische aus dem Mittelmiozän (Tarchan) von NordAnatolien (Türkei). Mitteilungen der Bayerischen Staatssammlung für Paläontologie und historischer Geologie 31, 69-80.

Smith, W. L. \& Craig, M. T. (2007). Casting the percomorph net widely: the importance of broad taxonomic sampling in the search for the placement of serranid and percid fishes. Copeia 2007, 35-55.

Smith, W. L. \& Wheeler, W. C. (2004). Polyphyly of the mail-cheeked fishes (Teleostei: Scorpaeniformes): evidence from mitochondrial and nuclear sequence data. Molecular Phylogenetics and Evolution 32, 627-646.

Springer, V. G. \& Orrell, T. M. (2004). Study of the dorsal gill-arch musculature of teleostome fishes, with special reference to the Actinopterygii, Appendix. Phylogenetic analysis of the families of acanthomorph fishes based on dorsal gill-arch muscles and skeleton. Bulletin of the Biological Society of Washington 11, 237-360.

Steindachner, F. (1860). Beiträge zur Kenntniss der fossilen Fisch Fauna Österreichs. II. Über einen fossilen Lephobranchier von Radoboj in Croatien. Sitzungsberichte der Kaiserlichen Akademie der Wissenschaften 40, 571-572.

Stölting, K. N. \& Wilson, A. B. (2007). Male pregnancy in seahorses and pipefish: beyond the mammalian model. BioEssays 29, 884-896.

Teske, P. R. \& Beheregaray, L. B. (2009). Evolution of seahorses' upright posture was linked to Oligocene expansion of seagrass habitats. Biology Letters 5, 521-523.

Teske, P. R., Cherry, M. I. \& Matthee, C. A. (2004). The evolutionary history of seahorses (Syngnathidae: Hippocampus): molecular data suggest a West Pacific origin and two invasions of the Atlantic Ocean. Molecular Phylogenetics and Evolution 30, 273-286.

Teske, P. R., Hamilton, H., Palsboll, P. J., Choo, C. K., Gabr, H., Lourie, S. A., Santos, M., Sreepada, A., Cherry, M. I. \& Matthee, C. A. (2005). Molecular evidence for longdistance colonization in an Indo-Pacific seahorse lineage. Marine Ecology Progress Series 286, 249-260.

Teske, P. R., Hamilton, H., Matthee, C. A. \& Barker, N. P. (2007). Signatures of seaway closures and founder dispersal in the phylogeny of a circumglobally distributed seahorse lineage. BMC Evolutionary Biology 7, 138.

Thiel, R., Eidus, I. \& Neumann, R. (2009). The Zoological Museum Hamburg (ZMH) fish collection as a global biodiversity archive for elasmobranchs and actinopterygians as well as other fish taxa. Journal of Applied Ichthyology 25, 9-32.

Wilson, A. B. (2006). Genetic signature of recent glaciation on populations of a near-shore marine fish species (Syngnathus leptorhynchus). Molecular Ecology 15, 1857-1871.

Wilson, A. B., Vincent, A., Ahnesjö, I. \& Meyer, A. (2001). Male pregnancy in seahorses and pipefishes (family Syngnathidae): rapid diversification of paternal brood pouch morphology inferred from a molecular phylogeny. Journal of Heredity 92, 159-166.

Wilson, A. B., Ahnesjö, I., Vincent, A. C. J. \& Meyer, A. (2003). The dynamics of male brooding, mating patterns, and sex roles in pipefishes and seahorses (family Syngnathidae). Evolution 57, 1374-1386.

Wilson, N. G. \& Rouse, G. W. (2010). Convergent camouflage and the non monophyly of 'seadragons' (Syngnathidae: Teleostei): suggestions for a revised taxonomy of syngnathids. Zoologica Scripta 39, 551-558.

Woodall, L. (2009). Population genetics and mating systems of European seahorses Hippocampus guttulatus and Hippocampus hippocampus. $\mathrm{PhD}$ Thesis, University of London, Royal Holloway, UK.

Zalohar, J., Hitij, T. \& Kriznar, M. (2009). Two new species of seahorses (Syngnathidae, Hippocampus) from the Middle Miocene (Sarmatian) Coprolitic Horizon in Tunjice Hills, Slovenia: the oldest fossil record of seahorses. Annales de Paleontologie 95, 71-96.

\section{Electronic Reference}

Froese, R. \& Pauly, D. (2010). FishBase. Available at www.fishbase.org 